\title{
A UTILIZAÇÃo DE MAPAS MENTAIS NO ENSINO-APRENDIZAGEM DE Ciências: UM CASO de alunos nOS ANOS FINAIS, NUMA ESCOLA PRIVAdA EM ForTAleza - CEARÁ
}

THE USE OF MIND MAPS IN THE TEACHING AND LEARNING PROCESS OF SCIENCE: THE USE OF MIND MAPS IN THE TEACHING-LEARNING OF SCIENCE IN STUDENTS IN THE FINAL YEARS AT A PRIVATE SCHOOL IN FORTALEZA - CEARÁ

EL USO DE MAPAS MENTALES EN LA ENSEÑANZA-APRENDIZAJE DE LAS CIENCIAS: UN CASO DE ESTUDIANTES DE ÚLTIMO AÑO, EN UNA ESCUELA PRIVADA EN FORTALEZA CEARÁ

\section{Brenno Ramy Teodósio da \\ Silva \\ iD 9}

Especialista em Ensino de Química (UECE)

Professor da Rede de Ensino

Particular em Fortaleza/CE

Discente do Programa em Ensino

de Ciências e Matemática

(PGECM/IFCE Campus Fortaleza)

brennoramy90@gmail.com

\section{Ana Karine Portela \\ Vasconcelos \\ (iD) 9}

Doutora em Engenharia Civil

(UFC)

Professora de Química do Instituto

Federal do Ceará (IFCE)

Docente do Programa em Ensino

de Ciências e Matemática

(PGECM/IFCE Campus Fortaleza)

karine@ifce.edu.br

\section{Aurelice Barbosa de \\ Oliveira

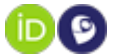

Doutora em Bioquímica (UFC)

Professora do Curso de Química

da Universidade Estadual do Ceará (UECE)

aurelice.barbosa@uece.edu.br

\begin{abstract}
Resumo
Considerando a superação do ensino tradicional e passivo, é necessário se trabalhar com metodologias que envolvam os alunos e proporcionem uma efetiva aprendizagem. O objetivo desta pesquisa foi investigar as contribuições e desafios apresentados por discentes do ensino fundamental quanto ao uso da metodologia ativa com mapas mentais como recurso nas aulas de Ciências. A pesquisa desenvolvida foi qualitativa, utilizou-se como método a pesquisa participante, não de forma geral, mas de acordo com a realidade dos alunos. O local de pesquisa deu-se numa escola da rede particular de ensino. A coleta e análise dos dados ocorreu obtidos foram por meio de questionários de sondagem, ou seja, buscando saber se o discente possui algum conhecimento prévio, a fim de elencar as contribuições da metodologia após sua aplicação. A pesquisa executada levou à proposição de contribuições e desafios para uma realização de metodologia alternativa com o uso de mapas mentais.
\end{abstract}

Palavras-chave: Ensino-aprendizagem. Pesquisa participante. Mapas mentais.

Recebido em: 24 de maio de 2021 .

Aprovado em: 6 de dezembro de 2021.

Como citar esse artigo (ABNT):

SILVA, Brenno Ramy Teodósio da; VASCONCELOS, Ana Karine Portela; OLIVEIRA, Aurelice Barbosa de. A utilização de mapas mentais no ensino-aprendizagem de Ciências: um caso de alunos nos anos finais, numa escola privada em Fortaleza Ceará. Revista Prática Docente, v. 6, n. 3, e096, 2021. http://doi.org/10.23926/RPD.2021.v6.n3.e096.id1190 


\section{Abstract}

Considering the overcoming of traditional and passive education, it is necessary to work with methodologies that involve students and provide effective learning. The objective of this research was to investigate the contributions and challenges presented by elementary school students regarding the use of active methodology with mind maps as a resource in Science classes. The research developed was qualitative, participatory research was used as a method, not in general, but according to the students' reality. The research site took place in a private school. The collection and analysis of the data occurred were obtained through survey questionnaires, that is, seeking to know if the student has any prior knowledge, in order to list the contributions of the methodology after its application. The research carried out led to the proposition of contributions and challenges for the realization of an alternative methodology using mind maps.

Keywords: Teaching-learning. Participatory research. Mental maps.

\section{Resumen}

Considerando la superación de la educación tradicional y pasiva, es necesario trabajar con metodologías que involucren a los estudiantes y proporcionen un aprendizaje efectivo. El objetivo de esta investigación fue investigar los aportes y desafíos que presentan los estudiantes de primaria en cuanto al uso de la metodología activa con mapas mentales como recurso en las clases de Ciencias. La investigación desarrollada fue cualitativa, se utilizó como método la investigación participativa, no en general, sino de acuerdo con la realidad de los estudiantes. El sitio de investigación se llevó a cabo en una escuela privada. La recolección y análisis de los datos ocurridos se obtuvo a través de cuestionarios de encuestas, es decir, buscando saber si el estudiante tiene algún conocimiento previo, con el fin de enumerar los aportes de la metodología luego de su aplicación. La investigación realizada condujo a la propuesta de aportes y desafíos para la realización de una metodología alternativa utilizando mapas mentales.

Palabras clave: Enseñanza-aprendizaje. Investigación participante. Mapas mentales. 


\section{INTRODUÇÃO}

Estudos apontam que discentes da atualidade apresentam grande engajamento quando se aplicam metodologias ativas, uma vez que propiciam uma participação mais efetiva dos mesmos, passando a desempenhar um papel crítico na questão cognitiva, desenvolvendo, assim, habilidades necessárias para acrescentar em sua rotina diária. No entanto, a metodologia de ensino habitualmente utilizada é a tradicional e isso acaba gerando uma pequena aversão a ela. Essa metodologia concentra-se na figura do professor como agente mediador de informações em aulas expositivas.

O formato tradicional de ensino é um dos motivos de crítica por muitos pesquisadores da área da educação, pois este método acaba limitando e não permitindo que haja espaço para que os estudantes possam se manifestar e redimensionar várias ideias, gerando, consequentemente, um baixo índice de aprendizagem, tendo em vista que os próprios alunos afirmam não sentir estímulo em dar sequência aos estudos. Nessa perspectiva, as metodologias ativas aplicadas em sala de aula representam um fator que influencia o processo de compreensão, já que novas informações serão entendidas e armazenadas na proporção qualitativa da estrutura cognitiva prévia do aluno, construindo uma aprendizagem significativa (MOREIRA; MASINI, 2006).

Observando todo o contexto, as atividades ativas se estabelecem como um poderoso recurso didático para que o ensino de Ciências ocorra de forma mais ambientada à realidade do aluno, viabilizando que compreendam não apenas a teoria envolvida no problema, mas também sua importância para a sociedade (BATISTA; NASCIMENTO, 2011). Diante dessa problemática, as aulas alternativas aplicadas em sala podem contribuir com o método tradicional, facilitando a compreensão dos alunos.

Uma abordagem proposta na literatura, podendo ser inserida em conjunto com o método tradicional de ensino, que gera um ambiente proveitoso para o desenvolvimento das habilidades, bem como uma participação efetiva por parte dos estudantes, é a aplicação da metodologia ativa com a estratégia dos mapas mentais, a partir dos mapas conceituais que se enraízam com um tema central do início, de maneira mais vertical, até conceitos mais específicos, ao final, desenvolvida por Joseph Novak e seu grupo de pesquisa da Universidade de Cornell, em 1972.

Nesse sentido, nos próximos parágrafos, descreve-se o que são metodologias ativas, sua relação com mapas mentais e as vantagens de associá-las com o método tradicional de ensino, 
propondo como objetivo geral a investigação de contribuições e desafios que serão apresentados pelos alunos do ensino básico quanto ao uso da metodologia dos mapas mentais como recurso didático nas aulas de Ciências. Por fim, apresenta as discussões dos dados obtidos, mediante aplicação da metodologia ativa com discentes do ensino fundamental que compõem a rede privada de ensino. A pesquisa teve uma abordagem qualitativa, elegeu-se como metodologia de pesquisa a participante, ou seja, envolvendo os discentes, conforme suas realidades para o centro do estudo.

\section{A APRENDIZAGEM SIGNIFICATIVA E OS MAPAS MENTAIS}

A utilização dessas atividades de aprendizagem, trabalhando a parte cognitiva e persuasiva dos alunos, contribui para uma aprendizagem mais eficiente. Através da confecção dos mapas mentais, aquele conteúdo antes chamado de "inacessível", geralmente apresentado pelo método tradicional de ensino, passa a despertar maior interesse, dado que, além de tirar aquele acúmulo de conteúdos abordado, cria-se, também, uma facilidade, pela simples organização de ideias, como também a produção de desenhos, imagens, entre outros, em uma simples folha, estimulando a sua criatividade. Ao produzir o mapa mental, a facilidade é tamanha que conceitua até um assunto mais complexo - a percepção que este se torna mais fácil após uma organização de ideias.

Ademais, durante as aulas alternativas promulgados pelo professor, com um dinamismo adequado, seria possível mostrar, ao aluno, como de fato um indivíduo se comporta, dentro de suas funcionalidades. A aplicação da metodologia abordada contribui, ainda, para uma possível liderança no futuro trabalho, porque auxilia na organização de ideias, no trabalhar em equipe, tomando decisões importantes para uma melhoria da empresa, observar mais a sua volta e o pensamento crítico em relação às opiniões da sociedade.

Com esta ideia, a Teoria da Aprendizagem Significativa (TAS) proposta por David Ausubel vai se concretizando quando o conteúdo apresentado pelo professor passa a se conectar ao que o discente já conhece, favorecendo um conceito relevante, promovendo uma facilidade na aquisição deste conhecimento, considerando todos os fatores que rondam a sala de aula e que possam influenciar na qualidade da aprendizagem (SARAIVA et al, 2017).

Para uma eficácia no processo de conhecimentos é importante o acompanhamento sobre os métodos de ensino e seus recursos necessários a fim de que os resultados se tornem mais positivos. No ramo educacional, a busca incessante por novas tendências e motivações facilitam a continuidade do aprendizado por agentes que participam de forma direta e indireta, trazendo 
substituições da metodologia tradicional praticada contemporaneamente (GALANTE, 2013). Segundo o autor, o sistema educacional perpassa por um conjunto de momentos que se resume em um contexto conteudista, no qual o mais importante é passar ao aluno uma exorbitante gama de conceitos sem entender os processos dele, que precisa de construções ao longo do seu crescimento, tais como: cultural, intelectual e racional.

Por outro lado, o método da aprendizagem significativa se dá por meio da interação de forma participativa, sem regras e não arbitrária das ideias com o conhecimento prévio do aluno. Para Moreira (2012), essa ideia já existente é nomeada de "subsunçor" ou "ideia-âncora", uma terminologia, provindo de um pensamento específico, já existente na estrutura de conhecimentos do indivíduo, que permite dar significado a um novo conhecimento que é apresentado de forma rápida ou por ele mesmo descoberto.

O subsunçor pode ter maior ou menor estabilidade cognitiva, pode estar mais ou menos diferenciado em termos de significados. Como o processo é interativo, quando serve de amparo para novos conhecimentos, se modifica, adquirindo novas acepções, contribuindo ainda mais para os conhecimentos iniciais dentro da noção do indivíduo (MOREIRA, 2012). Como contribuição, Rogers (2001) conceitua a aprendizagem significativa da seguinte maneira:

Por aprendizagem significativa entendo uma aprendizagem que é mais do que uma acumulação de fatos. É uma aprendizagem que provoca uma modificação, quer seja no comportamento do indivíduo, na orientação futura que escolhe ou nas suas atitudes e personalidade. É uma aprendizagem penetrante, que não se limita a um aumento de conhecimento, mas que penetra profundamente todas as parcelas da sua existência (ROGERS, 2001, p. 1).

Os mapas mentais utilizam de palavras-chave, cores e imagens em uma estrutura fixa que começa a espalhar a partir do centro. São comparados aos Mapas Geográficos, por usar-se cores, linhas, símbolos, imagens e palavras nestes mapas. Existe uma ideia central, por exemplo, sendo o centro da cidade, e ideias secundárias, as ruas que formam esta cidade. É importante destacar que os mapas mentais são ferramentas que permitem organizar pensamentos e facilitar tanto a introdução como a extração de informações no cérebro. Portanto, o mapa mental reforça a capacidade de memorização, organização, análise e síntese (ONTORIA; LUCKE; GÓMEZ, 2006). Em seguida, visualiza-se um modelo proposto: 
Figura 1 - Modelo de mapa mental

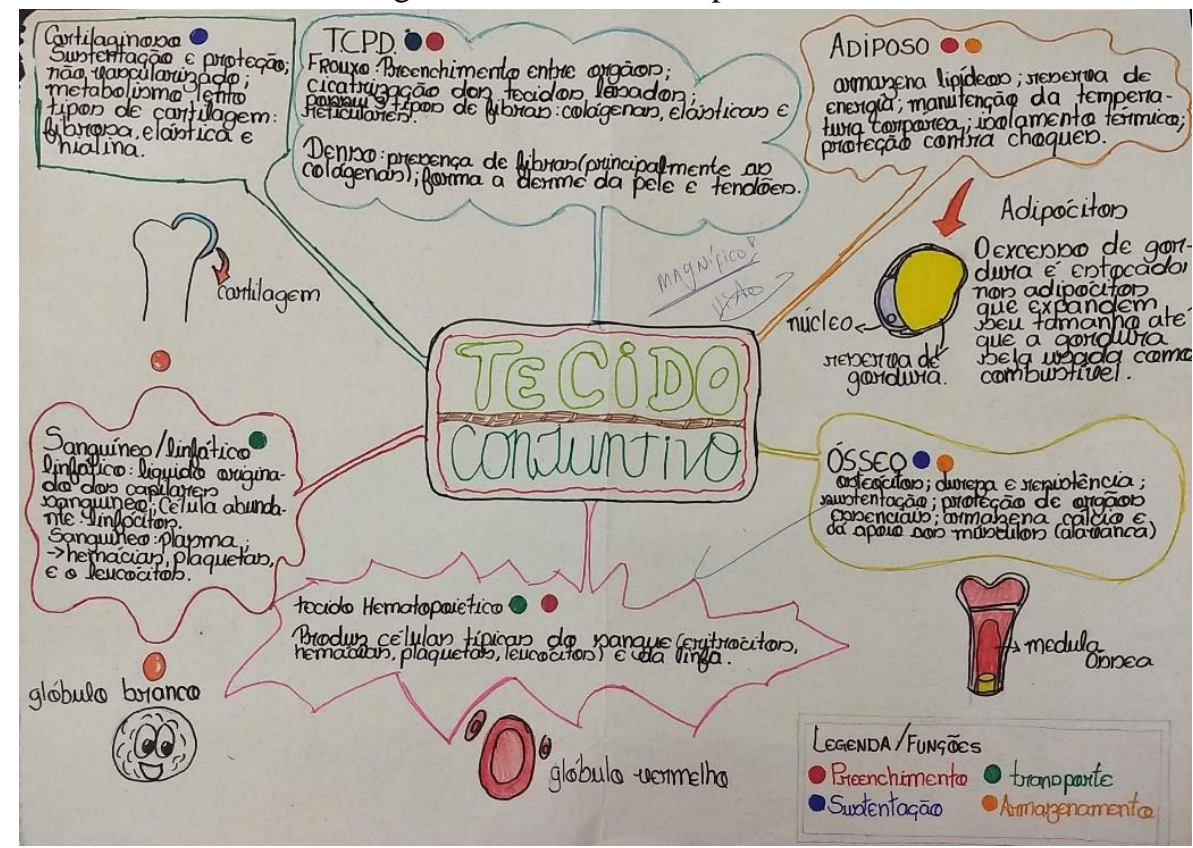

Fonte: Elaborado por um dos discentes pesquisados (2018).

Os mapas mentais são como uma ferramenta de pensamento e não precisam de qualquer tecnologia para ser confeccionado, podendo ser desenhado à mão, transformando uma lista de conteúdos desordenados e exaustivos em um modelo de conhecimento de fácil memorização e conteúdos sucintos e objetivos de forma ordenada. Um mesmo assunto pode originar distintos mapas mentais, elaborados por uma mesma pessoa ou por pessoas diferentes, posto que depende da forma como o pensamento é desenvolvido ou estruturado referente ao tema central, variando também conforme o conhecimento que a pessoa que o elaborará detém e sua forma de particionar e organizar informações relevantes ao tema do mapa (KEIDANN, 2013).

\section{Metodologia}

A pesquisa teve a abordagem com predominância qualitativa, manteve-se contato direto com os sujeitos, ambientes e situações que fazem parte da referida proposta, com meio de observação no comportamento do discente perante a metodologia da sala de aula invertida.

De acordo com Saraiva (2017), percebe-se que, ao longo do tempo, o ensino de Ciências passou por várias modificações, dentre elas, a finalidade dos conteúdos abordados, assim como as metodologias que buscam facilitar o conhecimento dos discentes.

Escolheu-se como método de pesquisa a participante, não de forma integral, mas com adaptações para a realidade dos pesquisadores. A pesquisa participante busca o envolvimento do sujeito na análise da própria realidade. 
Oliveira e Queiroz (2007) afirmam que a pesquisa participante é,

[...] definida como uma proposta de pesquisa, aonde os próprios sujeitos a ela pertinentes começam a se envolver de maneira ativa à construção de conhecimentos e na busca de soluções definitivas para situações apresentadas [...]. Nesse tipo de metodologia, o papel do sujeito da pesquisa é mudado: ele não é somente estudado, mas também é participante efetivo de todo o processo. Muda-se também o papel do pesquisador: ele não é apenas o que entende do assunto durante a pesquisa. (OLIVEIRA; QUEIROZ, 2007, p. 675).

A pesquisa foi desenvolvida em uma escola particular, de classe média, circuncidada por lojas e residências, no município de Fortaleza, capital do estado do Ceará, nordeste do Brasil. A escola possui turmas da educação infantil ao pré-vestibular, funcionando nos turnos manhã e tarde.

O estudo foi realizado em duas turmas do oitavo ano do ensino fundamental (anos finais), a abordagem do ensino voltou-se para o conteúdo de Ciências. O motivo da escolha das turmas deu-se em função das notas baixas e tempo hábil para realizar o método proposto.

As aulas foram ministradas por um dos autores deste trabalho, nas duas turmas, intituladas como turma A (manhã) e B (tarde), durante o primeiro semestre de 2018. As turmas A e B, totalizando 45 alunos, foram submetidas a diferentes metodologias de ensino. A turma A seguiu apenas com o método tradicional de ensino, como uso de lousa e explanação de conteúdo. Para a turma B, além das aulas expositivas, trabalhou-se, com ela, a confecção de mapas mentais após cada aula. Os conteúdos abordados durante o período da pesquisa foram: Citologia, Histologia, Sistemas Digestório, Respiratório e Cardiovascular.

No que se refere ao desenvolvimento da pesquisa, dividiu-se em três etapas:

A $1^{\text {a }}$ etapa, em data anteriormente marcada, iniciou com a explicação sobre o que são mapas mentais e, posteriormente, aplicou-se de um questionário de sondagem, constituído de 5 questões objetivas, com o intuito de coletar as impressões dos alunos acerca da disciplina de Ciências. A $2^{\mathrm{a}}$ etapa teve início uma semana a posteriori.

A $2^{\mathrm{a}}$ etapa consistiu na ministração de aula sobre os conteúdos citados acima, em cinco semanas, às quintas-feiras, no horário da disciplina, nos turnos manhã e tarde, para as turmas A e B, seguindo suas metodologias diferenciadas. Após cada aula, os alunos realizavam atividades de casa para a fixação do conteúdo. A turma A praticava o que aprendeu com atividades propostas em sala, como exercícios do livro didático; a turma B com a confecção de mapas mentais.

A $3^{\text {a }}$ etapa compreendeu a aplicação de um questionário de avaliação, com 6 questões objetivas, analisando se a metodologia utilizada durante as aulas contribuiu para facilitar a 
compreensão nos conteúdos de Ciências. Após a coleta de dados dos questionários e as aulas ministradas, realizou-se a análise qualitativa.

\section{ReSUltados E DISCUSSÕES}

Inicialmente, serão apresentados os resultados e discussão para o questionário de sondagem e, na sequência, para o questionário de avaliação. A análise dos resultados para o questionário de sondagem considerou o total de alunos (turma A e B), enquanto a análise dos resultados para o questionário de avaliação comparou a evolução cognitiva entre as turmas A e B.

\subsection{QUESTIONÁRIO DE SONDAGEM}

Para a análise e discussão dos resultados do questionário de sondagem foram considerados os 45 participantes da pesquisa. Os resultados do questionário de sondagem são apresentados através de gráficos para cada pergunta, seguidos de uma análise crítica.

Em relação à primeira questão, os alunos que optavam pela resposta "sim", justificavam seguindo afirmações-chaves, assim como os alunos que optavam por "não" necessitavam justificar da mesma maneira. As afirmações-chaves foram as seguintes:

Alunos que respondiam a alternativa "Sim":

1.1) Sentiu-se estimulado a conhecer assuntos de Ciências abordados no cotidiano;

1.2) É uma ciência que pode ser aplicada no cotidiano/aspecto experimental;

1.3) É importante para a utilização da futura profissão.

Alunos que respondiam a alternativa "Não":

1.4) Dificuldades em compreender o conteúdo/Muita memorização;

1.5) Falta nos conhecimentos básicos em interpretação textual;

1.6) Devido à má formação da série anterior, sente-se prejudicado em compreender a matéria de Ciências.

Os 22 alunos (49\%) que optaram pelo "sim" apresentaram respostas diferentes para justificar o apreço pela disciplina. Destes, 12 alunos (54\%) disseram que se sentem estimulados a conhecer assuntos de Ciências abordados no cotidiano; três alunos (14\%) disseram gostar de Ciências por ser uma ciência da vida, em que o conhecimento da área exige muito raciocínio e compreensão, possuindo aspecto na parte experimental que comprova a eficácia; os demais, no caso, 7 alunos (32\%), consideram que a disciplina é muito importante para a utilização de suas respectivas e futuras profissões, como exemplo (Medicina, Enfermagem, Nutrição, Engenharia, etc.). 
Os outros 23 alunos (51\%) que disseram não gostar da disciplina optaram por três justificativas diferentes. A primeira justificativa, escolhida por 13 alunos (56\%), indicou que as dificuldades da disciplina de Ciências estão relacionadas ao grande trabalho na memorização, bem como uma gama de conteúdos abordados. A segunda justificativa, apontada por 5 alunos (22\%), referiu-se à não compreensão da disciplina devido à falta de prática na leitura, evidenciando um analfabetismo funcional (quando o aluno realiza a leitura e não compreende a sua contextualização). A terceira justificativa, selecionada por 5 alunos (22\%), indicou que o desinteresse pela disciplina de Ciências está relacionado à falta de dedicação por parte dos alunos em séries anteriores, resultando em dificuldades para entender a matriz da disciplina. A Figura 2 apresenta as respostas dadas pelos alunos em relação à primeira pergunta.

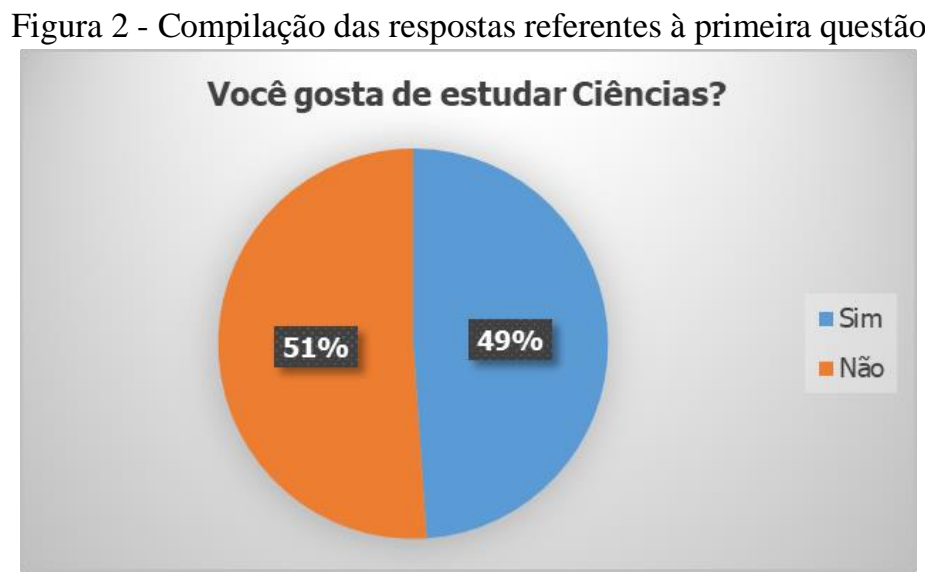

Fonte: Elaborado durante a pesquisa (2018).

Analisando todas as justificativas, é essencial frisar que os principais motivos dos alunos não gostarem da disciplina de Ciências estão associados à fragilidade da interpretação textual, no caso, a leitura e a compreensão dela, bem como a parte matemática do processo, provindo das bases adquiridas nas séries anteriores. Outro ponto importante é o professor estimular sempre seu aluno a entrar no "mundo da disciplina", quer dizer, buscar sempre entendê-la através de pesquisas, entre outras alternativas de estudo, pois a disciplina, às vezes, torna-se muito abstrata, dificultando a questão cognitiva do mesmo, como aborda Konzen,

Quando um professor está atento aos seus alunos e a eles dá oportunidades de desenvolverem habilidades, deixa-os mais livres para fazerem perguntas e questionar sobre os mistérios do mundo naturalista, com isto, estes alunos passam a ter condições de observar, refletir e experimentar ao mesmo tempo em que passam a integrar estas habilidades do pensamento naturalista em várias outras disciplinas. (KONZEN, 2009, p. 34). 
Então, as novas metodologias de ensino vêm facilitar o poder de entendimento do discente, ampliando o estímulo, entusiasmo e interesse dele. Assim, os conteúdos se tornam mais acessíveis e compreensíveis. A Figura 2 abaixo refere-se à segunda pergunta, tendo como finalidade compreender as dificuldades do aluno diante à disciplina ministrada.

De acordo com a figura, $45 \%$ sentem vergonha de falar o que não entenderam, isso devese ao medo de errar frente aos colegas, $42 \%$ dos alunos citaram a disciplina como algo não interessante, não gostam da mesma, e $2 \%$ dos alunos informaram que gostariam de saber mais da disciplina, porém, segundo eles, a metodologia utilizada pelo professor não facilita a compreensão do conteúdo.

A partir desses resultados, percebe-se que os alunos têm receio de elaborarem perguntas durante as aulas, por diversos motivos, dentre estes: receio do constrangimento por parte do professor, bullying por parte dos colegas da turma, desinteresse pela disciplina. Moreira (2013) esclarece que a clareza, a estabilidade e a organização do conhecimento prévio em um dado corpo de conhecimentos, em um certo momento, é o que mais influencia a aquisição significativa e cognitiva de novos conhecimentos nessa área, em um processo interativo, no qual o novo assunto e a nova abordagem ganham significados, se integram e se diferenciam em relação ao já existente que, por sua vez, adquire novos significados, fica mais estável, mais diferenciado, mais rico, mais capaz de ancorar novos conhecimentos.

O "não gostar de Ciências" presume que o aluno não busca alimentar o conhecimento através de pesquisas, a disciplina em si requer um aprofundamento nas atualidades, sempre se renova e, a cada ano, novos conteúdos são introduzidos dentro daqueles que se consolidaram e têm importância no ensino.

Figura 3 - Compilação das respostas referentes à segunda questão

Quais as principais dificuldades que você encontra quando o professor(a) aplica a matéria de Ciências e você não entende?

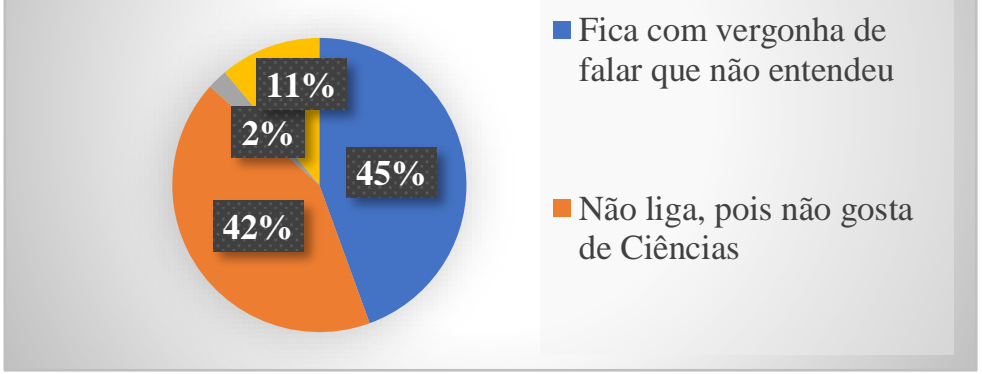

Fonte: Elaborado durante a pesquisa (2018). 
Na terceira questão, a figura mostra que $67 \%$ dos alunos acharam suficiente a quantidade de aulas durante a semana, contudo, $33 \%$ disseram que seria necessária a implementação de mais aulas por diversos motivos. A possibilidade de aumentar a quantidade de aulas se torna inviável, a escola segue a carga horária mínima anual imposta pelo Ministério da Educação (MEC), através do artigo 24, da Lei n ${ }^{\circ}$ 9.394/96, em que fica claro: “I - a carga horária mínima anual será de oitocentas horas, distribuídas por um mínimo de 200 dias de efetivo trabalho escolar, excluído o tempo reservado aos exames finais, quando houver” (BRASIL, 2017).

O artigo 34 da mesma lei diz: “A jornada escolar no Ensino Fundamental incluirá pelo menos quatro horas de trabalho efetivo em sala de aula, sendo progressivamente ampliado o período de permanência na escola" (BRASIL, 2017).

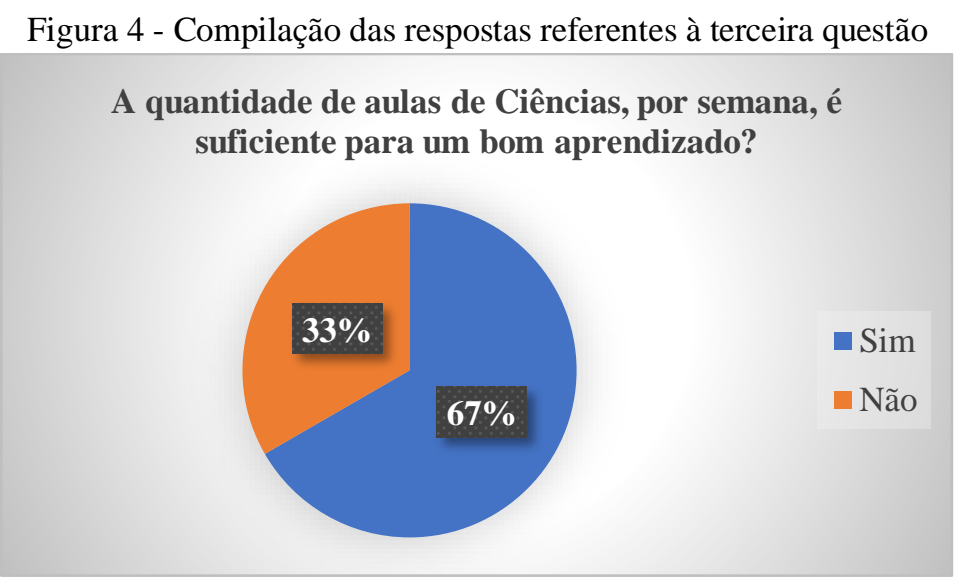

Fonte: Elaborado durante a pesquisa (2018).

A quarta questão apresenta a opinião dos alunos em relação à metodologia que mais contribui para a aprendizagem. A opção de escolher ambas não foi apresentada aos estudantes, o que levou alguns a marcar os dois itens propostos. A terceira ou quarta opção não foi abordada, uma vez que o objetivo é compreender, no ponto de vista do discente, se o modelo tradicional, com aula expositiva, é, de fato, melhor para a compreensão de conteúdos ministrados. A análise da figura demonstra que $22 \%$ dos alunos consideraram que as aulas expositivas/teóricas auxiliaram a compreensão do conteúdo. Entretanto, $78 \%$ do total de alunos ponderou que os conteúdos são mais fáceis de serem assimilados com a utilização de metodologias dinâmicas/práticas.

Mortimer e Scott (2002) explicam que, apesar de existir uma nova ênfase no discurso e na interação da abordagem em sala de aula, admite-se que relativamente pouco é conhecido sobre como os professores dão suporte ao processo pelo qual os estudantes constroem significados em salas de aula de Ciências, sobre como essas interações são produzidas e sobre 
como os diferentes tipos de discurso podem auxiliar a aprendizagem dos estudantes. Dentro deste viés, infelizmente, muitos professores utilizam de seus próprios recursos financeiros para recursos materiais com a finalidade de facilitar a compreensão do aluno.

Figura 5 - Compilação das respostas referentes à quarta questão

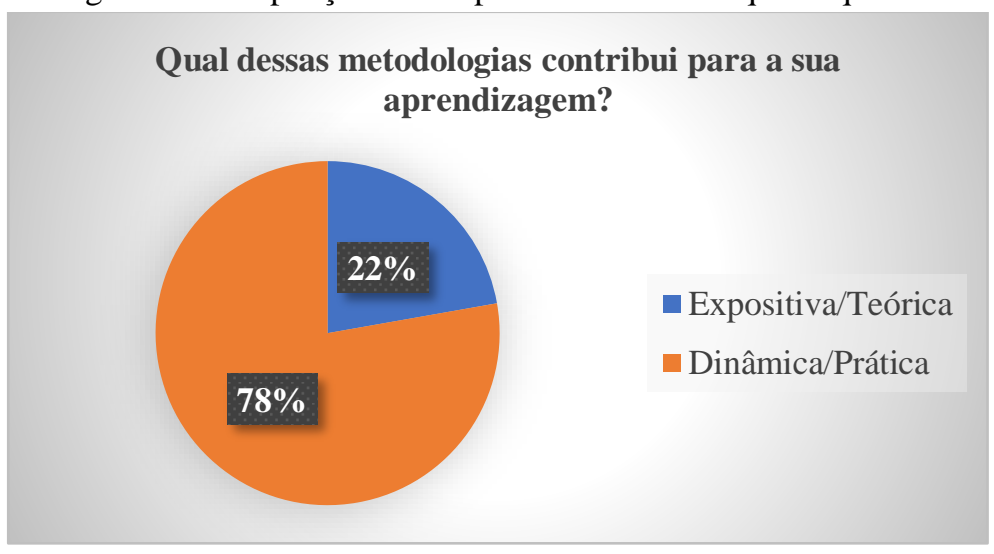

Fonte: Elaborado durante a pesquisa (2018).

A quinta questão refere-se ao estímulo para o estudo de Ciências, cujos resultados podem ser observados na Figura 6. Observa-se que, para 96\% dos alunos, o professor estimula bastante o estudo da área das Ciências. Dois alunos demonstraram-se insatisfeitos, sentindo-se não estimulados a estudar, de acordo com eles, o professor não reforça esse estímulo.

$\mathrm{O}$ verdadeiro professor exerce grande influência no processo educacional e, por esse motivo, precisa estar atento às limitações dos alunos. Logo, para uma ótima prática educacional satisfatória, faz-se mister que o professor reflita sobre pontos importantes, tais como o interesse do aluno, a relação com o professor, a metodologia usada para a abordagem dos conteúdos, a forma de assimilação desses conteúdos pelos alunos e os instrumentos de avaliação, fatores que podem contribuir para estimular ou desestimular o aluno no estudo da disciplina de Ciências. O que mais intriga é a grande quantidade de alunos que afirmam receber estímulos pelo professor, mesmo assim, a maioria não gosta ou não tem afinidade com a disciplina (LIMA; BARBOSA, 2015).

Certos fatores explicam a não-afinidade dos alunos com o ensino de Ciências. Um dos exemplos é o afastamento de familiares, o próprio discente não se sente estimulado em razão da falta de atenção dos pais ou responsáveis perante seus estudos. Os aparelhos eletrônicos, ultimamente, influenciam em seu cotidiano, os adolescentes contemporâneos ficam muito tempo interligados às redes sociais, o que impacta em seu não interesse nhoque diz respeito à pesquisa científica. Isso gera, também, aumento do comodismo, de não querer ir em busca de assuntos que se tratam no meio das Ciências Naturais. 
Figura 6 - Compilação das respostas referentes à quinta questão

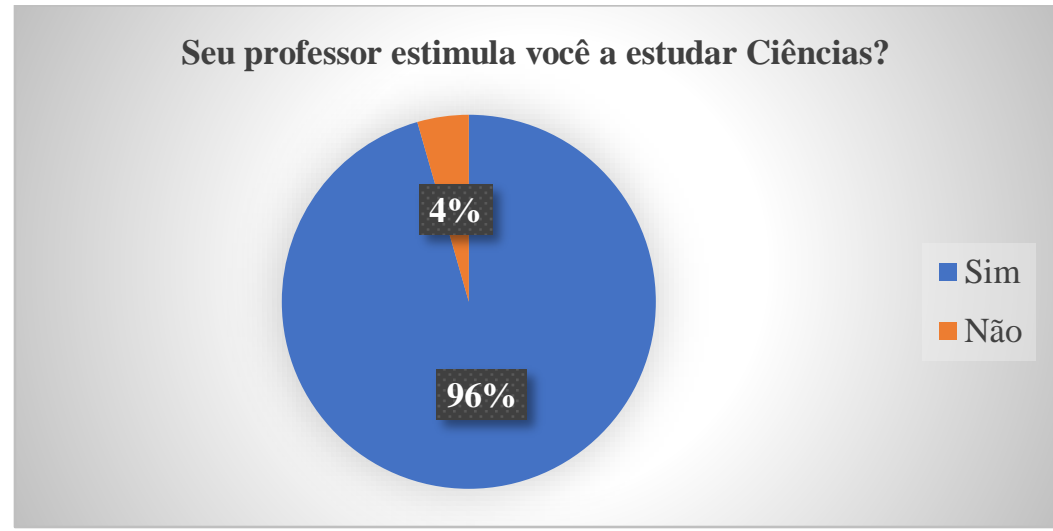

Fonte: Elaborado durante a pesquisa (2018).

\subsection{Questionário de Avaliação}

A sexta questão indagou se as aulas contribuíram para o aprendizado e observou-se grande diferença nas opiniões dos alunos em relação às abordagens realizadas durante os meses de fevereiro até maio. A Turma A apresentou 15 alunos insatisfeitos com a abordagem tradicional da aula, enquanto 3 alunos declararam que a aula em si facilitou bastante o aprendizado e, outros 2 alunos ficaram indecisos no quesito interesse nas aulas, por isso optaram por marcar a opção "um pouco". A Turma B mostrou-se satisfeita com a abordagem alternativa, haja vista que a maioria não demonstrava interesse nas aulas tradicionais anteriormente aplicadas. Apenas 1 aluno revelou que a abordagem da aula não favoreceu a aprendizagem, porque, consoante sua explicação, ambas as aulas são fáceis de compreender, em função do professor apresentar uma boa didática. A opção "um pouco" também foi escolhida por apenas 1 aluno, apontou que as aulas influenciaram de maneira pouco significativa em sua aprendizagem.

Em conformidade com Heckler, Saraiva e Oliveira Filho (2007), as animações são consideradas, por muitos, a solução dos vários problemas que os professores de Ciências enfrentam ao tentar explicar para seus alunos fenômenos abstratos, para serem visualizados através de uma descrição em palavras, e complicados para serem representados através de uma única figura. Elas possibilitam observar, em alguns minutos, a evolução temporal de um fenômeno que levaria horas, dias ou anos em tempo real, além de permitir, ao estudante, repetir a observação sempre que o desejar. Outrossim, é notório que o aluno na atualidade prefere animações que o leve a entender como determinado fenômeno se comporta em um certo lugar, facilitando o entendimento, colocando-o de maneira mais intuitiva. 
Verificou-se que os alunos da Turma A, em grande parte, não entendiam determinados assuntos apresentados pelo simples motivo de serem abstratos, com isso, a ineficácia da aprendizagem surge a partir desse momento. A turma B sentiu-se beneficiada, isso porque somou-se uma boa explicação em sala de aula ao fato de o professor autor ainda contar com o trabalho criativo dos mapas mentais no momento de cada explicação.

Figura 7 - Compilação das respostas referentes à sexta questão

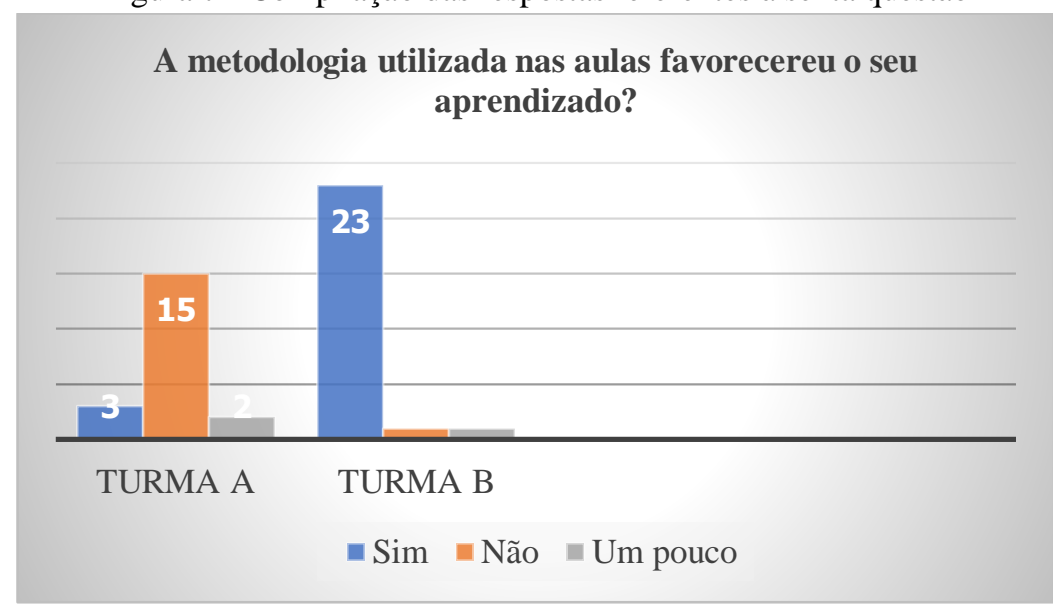

Fonte: Elaborado durante a pesquisa (2018).

A sétima questão indagou sobre as opiniões dos alunos frente às tarefas realizadas em suas residências. A figura mostra a divisão de opiniões entre os alunos da turma A, em que 9 alunos disseram que as atividades (exercícios no livro) facilitaram para o entendimento da disciplina; 9 alunos opinaram que os exercícios no livro não facilitaram a compreensão da disciplina e 2 alunos optaram pela opção "um pouco", pois afirmaram ter afinidade com a disciplina de Ciências, dependendo da metodologia empregada, conseguiam absorver com facilidade determinado conteúdo. Quanto aos alunos da turma B, um grande número, 22 alunos, afirmam que a confecção de mapas mentais referentes ao assunto abordado na aula anterior facilitou muito a compreensão do conteúdo. Apenas 1 aluno optou por "não", ele possuía dificuldade na compreensão de leitura e também organização dos desenhos apresentados no mapa; 2 alunos marcaram a opção "um pouco", como justificativa, alegaram que tanto os exercícios no livro quanto mapas mentais auxiliam no fácil entendimento, já que possuíam afinidade com a disciplina.

De acordo com Cicuto e Correia (2013), a diferenciação progressiva dos conceitos facilita a assimilação de novas informações durante a aprendizagem. Por esse motivo, é aconselhável começar a instrução com conceitos mais gerais sobre o assunto a ser abordado. Os detalhamentos devem ser feitos a partir deles, objetivando de que os alunos consigam 
compreender todas as partes do conteúdo sem perder a chance de relacioná-las com o todo. A diferenciação progressiva, que pode ser visualizada nos mapas mentais, é um conceito útil ao planejamento das atividades de ensino. Desta forma, a combinação da teoria de David Ausubel, que institui o uso dos mapas mentais, gera um ponto de partida favorável à criação de um processo de ensino que favoreça a aprendizagem significativa.

O mapa mental é uma abordagem nova no meio educacional. Ainda existe uma certa repulsa por professores a essa metodologia de ensino simplesmente por não a conhecer. Após o contato, nota-se que essa forma de aplicação é uma maneira bastante prática para o entendimento do aluno. Conforme Novak (2010), os seres humanos pensam, sentem, agem e todos esses elementos devem ser combinados na criação de novos conhecimentos, gerando o conhecimento prévio. Desse modo, o desafio educacional é gerenciar as seguintes formas de aprendizagem:

1. A aquisição de conhecimento (aprendizagem cognitiva);

2. A mudança na emoção ou sentimentos (aprendizagem afetiva); e

3. O ganho de aptidão física ou motora (aprendizagem psicomotora).

Figura 8 - Compilação das respostas referentes à sétima questão

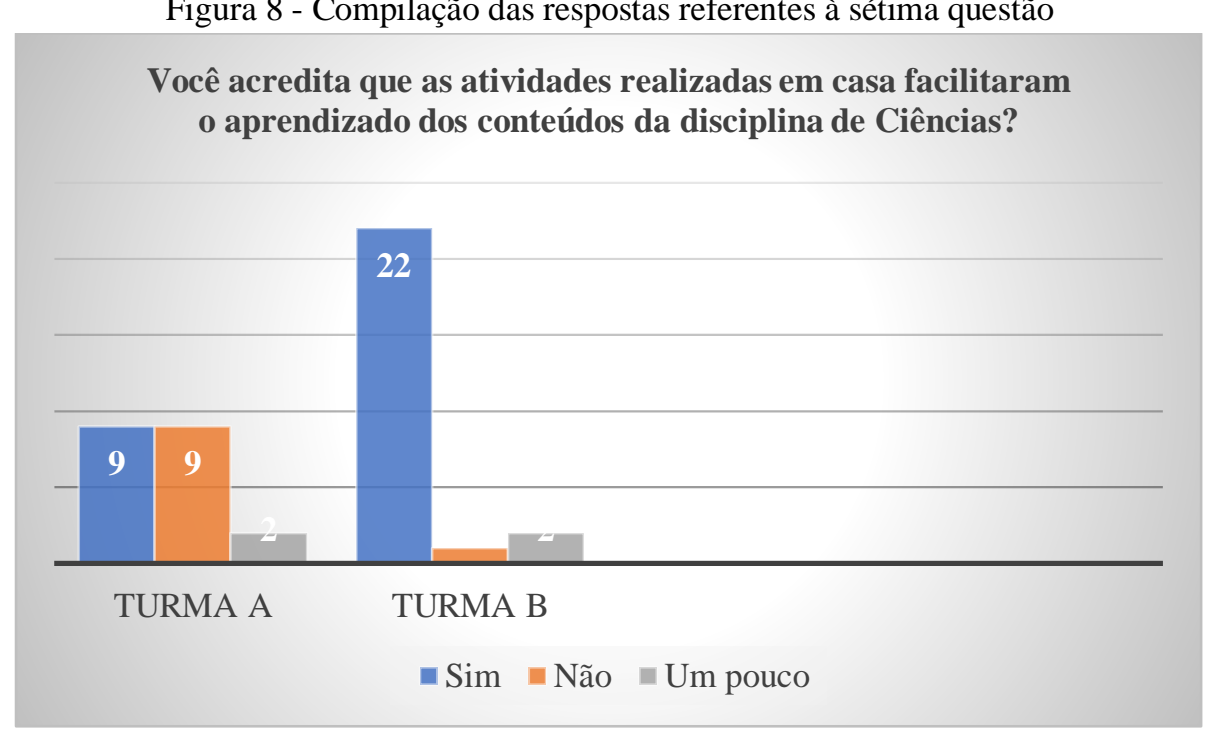

Fonte: Elaborado durante a pesquisa (2018).

A oitava questão, uma complementação da sétima questão, reflete o impacto que as atividades diferenciadas, realizadas em casa, para uma melhor fixação do conteúdo, causaram nos alunos. Tanto os exercícios do livro, quanto os mapas mentais, obrigaram o aluno a realizar uma pesquisa, todavia, a maneira de se sentir estimulado é o que difere nessa pergunta. $\mathrm{Na}$ Turma A, 17 alunos não se sentiram estimulados a realizar exercícios do livro, repercutindo na desmotivação a estudar Ciências, enquanto 3 alunos informaram que se sentiram estimulados. 
Os alunos da Turma B, em grande maioria, 23 alunos, reforçaram que, após a confecção de mapas mentais, se sentiram estimulados a estudar Ciências. Apenas 2 alunos não se sentiram motivados a estudar Ciências. A pergunta mostrou que, em relação aos alunos da manhã, os alunos da tarde passaram a estudar mais os conteúdos trabalhando a elaboração dos mapas mentais, visto que, durante a confecção, cada conceito é "destrinchado" e compreendido ponto a ponto. Segundo Beluzzo,

Toda pessoa tem por natureza a curiosidade e a criatividade, o que implica em constante questionamento das diferentes situações a que está sujeita a enfrentar e, para compreender a realidade em que vive, requer acesso e uso da informação de forma inteligente. Desse modo, se faz necessária a motivação dessas competências naturais e orientar o seu desenvolvimento sistemático e gradual, permitindo aumentar a disposição para a educação contínua e a capacidade de adquirir e inovar o conhecimento, o que pode ser sintetizado na aquisição de uma cultura da informação, do conhecimento e da aprendizagem (BELUZZO, 2006, p. 80).

Utilizar maneiras diferentes na abordagem do assunto de Ciências, desviando um pouco da metodologia tradicional, apresenta-se como uma novidade ao aluno, e é em busca de novidades que ele vive todos os dias, pelas motivações ao fácil acesso à internet. Porém, a questão prática auxilia o momento atual vivido por nossos jovens, e o mapa mental, como uma novidade no âmbito dos estudos, de maneira enxuta e prática, auxilia na compreensão.

Figura 9 - Compilação das respostas referentes à oitava questão

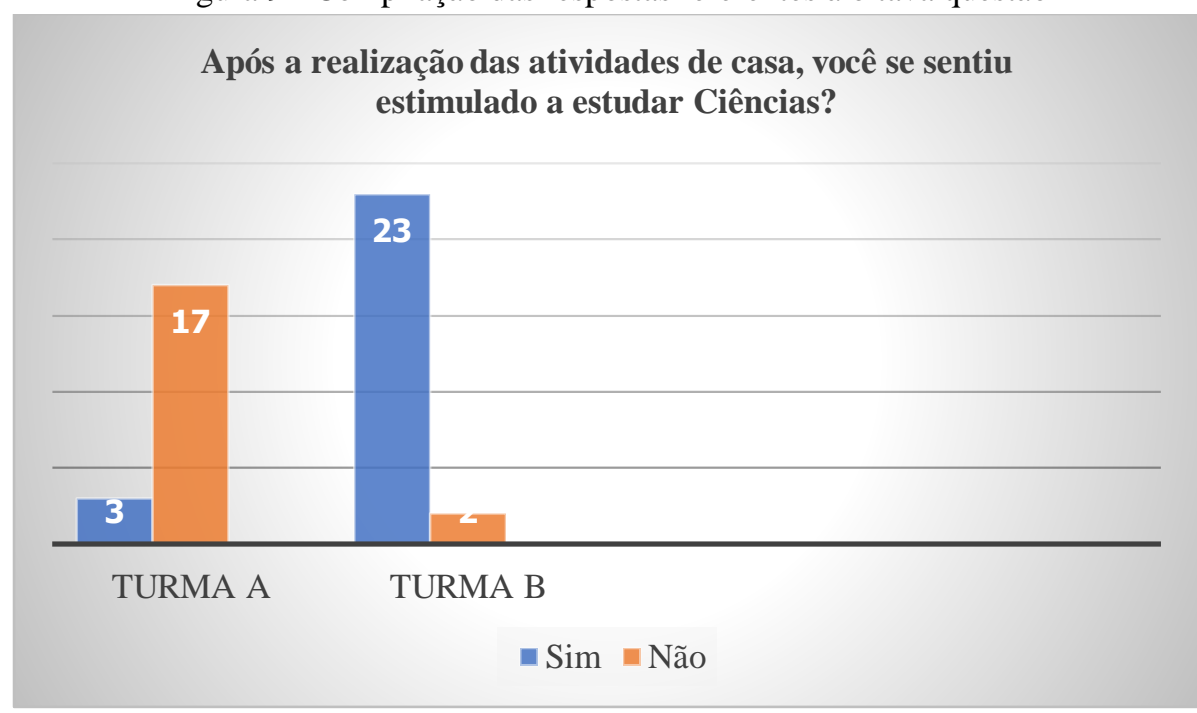

Fonte: Elaborado durante a pesquisa (2018).

Os resultados apresentados nas Figuras 10 e 11 referem-se apenas a turma B, pois apenas nesta turma foram realizadas aulas com a confecção de mapas mentais. A Figura 10 reflete a dificuldade na elaboração dos mapas mentais. Constatou-se que $40 \%$ dos alunos disseram sentir dificuldades ao elaborar o mapa mental. Sem embargo, 60\% dos alunos acharam fácil a elaboração do mapa mental. Os alunos que sentiram dificuldade ao elaborar o mapa mental 
foram questionados sobre as possíveis dificuldades e informaram que não se atentaram ao momento da explicação e não pesquisaram as instruções para a elaboração de um mapa mental. Os alunos que não tiveram dificuldades na elaboração esclareceram que se atentaram à instrução de elaboração e pesquisaram as diversas maneiras de se construir o mapa mental. Analisando a pergunta e também as respostas, um ponto interessante dos mapas mentais é que influenciam de modo significativo o intelecto, tendo em vista que os alunos que sentiram dificuldade passaram a pesquisar e tirar dúvidas no momento que confeccionaram seus respectivos mapas mentais.

Figura 10 - Compilação das respostas referentes à nona questão

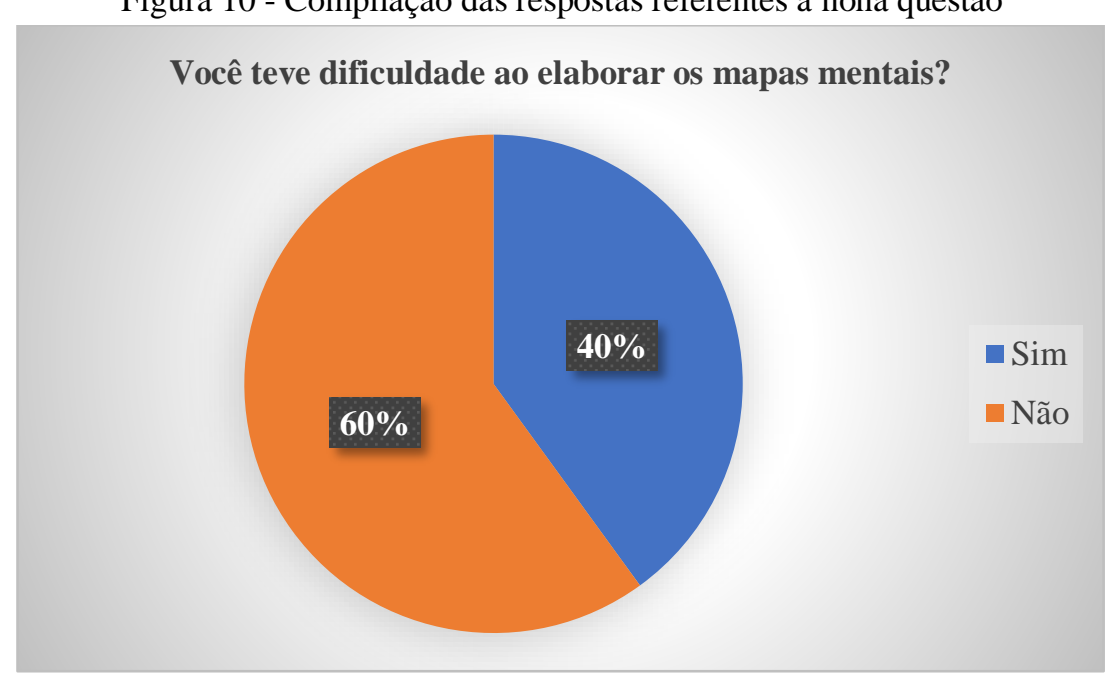

Fonte: Elaborado durante a pesquisa (2018).

A décima questão trouxe o questionamento sobre a aplicação dos mapas mentais, qual o conteúdo que os alunos mais fixaram, isto é, tiveram maior facilidade no momento da aprendizagem. Analisando a figura, 40\% dos alunos asseveraram que, após confeccionar os mapas mentais, o conteúdo que mais fixou foi sobre o assunto referente a órgãos; $32 \%$ disseram que o conteúdo mais fácil foi sobre sistemas; $16 \%$ optaram pelo conteúdo de citologia, informando ser mais fácil e $12 \%$ escolheram o conteúdo sobre histologia como o mais fácil dentre os demais.

É fácil interpretar essa diferença de opiniões. Primeiro, o assunto abordado sobre órgãos teve um maior contingente de votação devido à fácil compreensão, estudando seus conceitos, funcionalidade e doenças sexuais que podem ser adquiridas. O segundo mais votado foi sobre sistemas, por sua complexidade, o conhecimento é justamente a apresentação dos órgãos e a funcionalidade de todos em conjunto. O terceiro mais votado foi o conteúdo de citologia, essa disciplina se torna mais difícil que as demais pelo grande número de conceitos presentes, nomes 
muito complexos, os quais os alunos não conseguem assimilar se a aula for de maneira apenas expositiva. Nessa circunstância, os mapas mentais apresentam-se como uma opção para uma melhor absorção desse conteúdo. O último mais votado foi histologia, devido ao mesmo problema apresentado sobre o conteúdo de citologia e, claro, mais complexo, a definição de tecidos presume em um conjunto de células com determinadas funções especializadas.

Figura 11 - Compilação das respostas referentes à décima questão

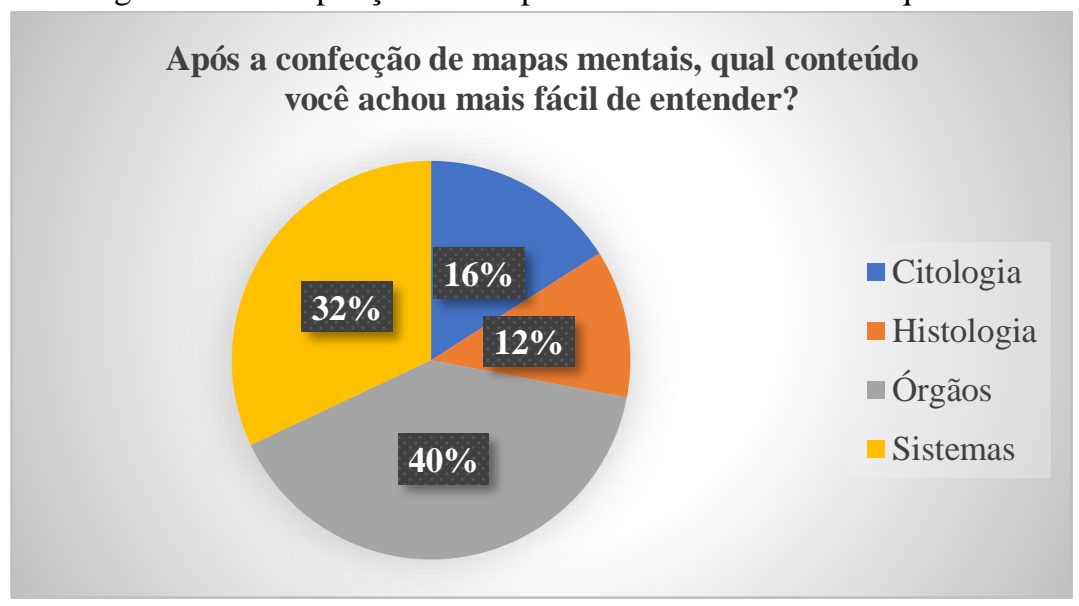

Fonte: Elaborado durante a pesquisa (2018).

Por sua vez, a décima primeira questão aborda a possibilidade de elaboração de um projeto futuro, no qual todas as disciplinas utilizassem mapas mentais para melhor compreensão. Após a aplicação dos mapas mentais na Turma B, percebeu-se grande satisfação dos alunos com a metodologia utilizada, evidenciada pelos $96 \%$ dos alunos que reiteraram a necessidade de outras disciplinas utilizarem essa ferramenta didática para fixar conteúdo. Disciplinas das Ciências Exatas e da Natureza como Matemática, Física e Química seriam compreendidas melhor com a utilização desse recurso, pois aproxima os conceitos mais abstratos em uma realidade de entendimento. Outras disciplinas que usam de muitos textos, como História e Geografia, também entrariam nessa aplicação. 
Figura 12 - Compilação das respostas referentes à décima primeira questão

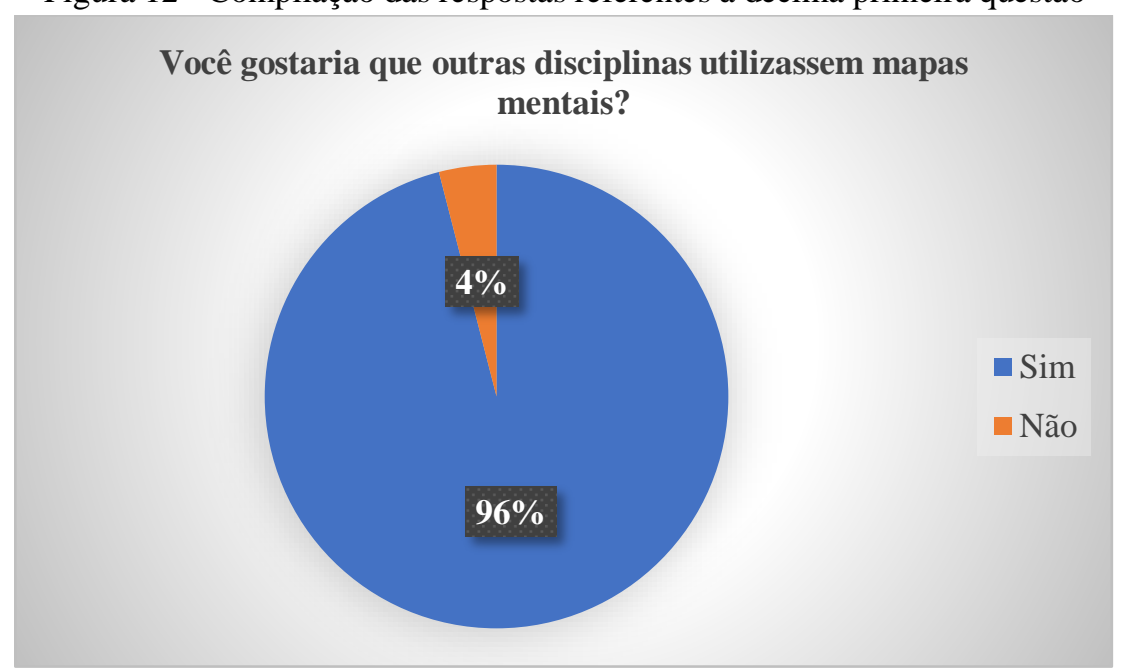

Fonte: Elaborado durante a pesquisa (2018).

\section{CONSIDERAÇõES FinAIS}

No presente artigo foi proposta a investigação do potencial das metodologias ativas tendo como instrumento metodológico os mapas mentais. Na análise dos resultados, verificouse que existe um forte potencial na compreensão dos discentes não apenas da aprendizagem conceitual, mas também de outros aspectos relevantes, como palavras utilizadas em nosso cotidiano, conhecendo seu significado. Com a aplicação do questionário de sondagem, constatou-se que muitos dos alunos não se sentem satisfeitos com a metodologia tradicional, mesmo tendo uma boa relação com o professor, este tipo de abordagem não favorecia o seu aprendizado. Após as respostas do questionário de avaliação, os resultados foram satisfatórios. Os alunos perceberam a importância do estudo de Ciências em suas vidas. Entre as duas metodologias, a das aulas alternativas foi a mais comentada entre os alunos, pois constou-se compreender mais devido ao estímulo adotado em aula.

Após todo o trabalho realizado, com discentes do oitavo ano tarde, valendo-se da utilização de mapas mentais confeccionados pelos estudantes sempre ao término do conteúdo abordado em sala, constatou-se que essa metodologia é uma excelente alternativa para o novo processo de ensino-aprendizagem nas escolas, por sua efetividade e, também, aderência não só na disciplina de Ciências, como também no envolvimento de outras disciplinas.

A utilização dessas atividades, trabalhando a parte cognitiva e persuasiva dos alunos, contribui para uma aquisição de conhecimentos mais eficiente. Através da confecção dos mapas mentais, o conteúdo antes chamado de "chato" passa a despertar um maior interesse, ademais, tira o acúmulo de conteúdos abordados, cria-se uma facilidade pela simples organização de 
ideias e, ainda, a produção de desenhos, imagens, entre outros, ou seja, estimula a sua criatividade. Ao produzir o mapa mental, a facilidade é tamanha, que conceitua até um assunto mais complexo, dando uma percepção de que se torna mais fácil após uma organização de ideias. A aplicação da metodologia abordada contribui para uma possível liderança no futuro trabalho, auxilia na organização de ideias, no trabalhar em equipe, na tomada de decisões importantes para uma melhoria da empresa, observar mais a sua volta, pensar criticamente em relação as opiniões da sociedade.

De modo geral, as aulas alternativas desempenham funções cognitivas e epistemológicas. A opinião dos alunos é trabalhar essa forma de aula em todas as disciplinas para uma melhor compreensão. Para os alunos, uma aula teórica não é a principal metodologia que facilita a sua aprendizagem, embora em algumas matérias os professores utilizem das aulas tradicionais como seu meio de ensino, sabendo explicar de forma fácil e compreensiva.

Por meio dos mapas mentais é possível identificar um percurso metodológico e fundamentos conceituais que os alunos aprenderam no decorrer da aplicação para resolver problemas propostos nas atividades cotidianas, apontando que esta metodologia permite a interação entre os aspectos conceituais e metodológicos, favorecendo seus respectivos desenvolvimentos cognitivos.

\section{REFERÊNCIAS}

BATISTA, Irinéa De Lourdes; NASCIMENTO, Eliana Guidetti Do. União da História da Ciência com o Vê de Gowin: um estudo na formação de professores das séries iniciais.

Revista Brasileira de Pesquisa em Educação em Ciências, v. 11, n. 2, p. 41-66, 2011. Disponível em: http:/www.fep.if.usp.br/ profis/arquivos/vienpec/CR2/p687.pdf. Acesso em: 15 jul. 2019.

BELUZZO, Regina Célia Baptista. O uso de mapas conceituais e mentais como tecnologia de apoio à gestão da informação e da comunicação: Uma área interdisciplinar da competência em informação. Revista Brasileira de Biblioteconomia e Documentação, São Paulo, v. 2, n. 2 , p. 78-89, 2006. Disponível em: https://rbbd.febab.org.br/rbbd/article/view/19. Acesso em: 17 maio 2018.

BRASIL. Ministério da Educação. Base Nacional Comum Curricular: educação é a base. Brasília, DF, 2017. Disponível em: http://basenacionalcomum.mec.gov.br/wpcontent/uploads/2018/02/bncc-20dez-site.pdf. Acesso em: 19 jan. 2018.

CICUTO, Camila Aparecida Tolentino; CORREIA, Paulo Rogério Miranda. Estruturas hierárquicas inapropriadas ou limitadas em mapas conceituais: um ponto de partida para promover a aprendizagem significativa. Aprendizagem Significativa em Revista, Porto Alegre, v. 3, n. 1, p. 1-11, 2013. Disponível em:

http://www.if.ufrgs.br/asr/artigos/Artigo_ID39/v3 n1_a2013.pdf. Acesso em: 20 fev. 2018. 
GALANTE, Carlos Eduardo da Silva. O uso de mapas conceituais e de mapas mentais como ferramentas pedagógicas no contexto educacional do ensino superior. In: SEMINÁRIO INTERNACIONAL SOBRE A SITUAÇÃO DA POLÍTICA EDUCACIONAL DO MERCOSUL, 2013, Assunção. Anais... Assunção, Paraguai, 2013. p. 40-61. Disponível em: https://www.inesul.edu.br/revista/arquivos/arq-idvol_28_1389979097.pdf. Acesso em: 20 maio 2018.

HECKLER, Valmir; SARAIVA, Maria de Fátima Oliveira; OLIVEIRA FILHO, Kepler de Sousa. Uso de simuladores, imagens e animações como ferramentas auxiliares no ensino/aprendizagem de óptica. Revista Brasileira de Ensino de Física, São Paulo, v. 29, n. 2, p. 267-273, 2007. Disponível em: https://www.scielo.br/pdf/rbef/v29n2/a11v29n2.pdf. Acesso em: 10 abr. 2018.

KEIDANN, Glaucia. Utilização de mapas mentais na inclusão digital. In: ENCONTRO DE EDUCOMUNICAÇÃO DA REGIÃO SUL, 2., 2013, Ijuí. Anais... Ijuí, RS: 2013. p. 1-15. Disponível em: <http://coral.ufsm.br/educomsul/2013/com/gt3/7.pdf >. Acesso em: 02 abr. 2018.

KONZEN, Isolde Inês Wagner. A Didática no ensino de Ciências Naturais. Porto Alegre, 2009.

LIMA, José Ossian Gadelha; BARBOSA, Lídia Kênia Alves. O ensino de química na concepção dos alunos do ensino fundamental: algumas reflexões. Exatas, v. 6, n. 1, p. 33-48, 2015. Disponível em: http://www2.uesb.br/exatasonline/images/V6N1pag33-48.pdf. Acesso em: 10 maio 2018.

MOREIRA, Marco Antônio. Aprendizagem significativa, organizadores prévios, mapas conceituais, diagramas $\mathrm{V}$ e unidades de ensino potencialmente significativas. Instituto de Física - UFRGS, Porto Alegre, RS, 2013.

MOREIRA, Marco Antônio; MASINI, Elcie Aparecida Fortes Salzano. Aprendizagem significativa: A teoria de David Ausubel. 2a ed. São Paulo: Centauro, 2006.

MORTIMER, Eduardo Fleury; SCOTT, Phillip H. Atividade discursiva nas salas de aula de ciências: uma ferramenta sociocultural para analisar e planejar o ensino. Investigações em Ensino de Ciências, Porto Alegre, v. 7, n. 3, p. 283-306, 2002. Disponível em: https://www.if.ufrgs.br/cref/ojs/index.php/ienci/article/view/562/355. Acesso em: 20 mai. 2018.

MOREIRA, Marco Antônio. O que é a final aprendizagem significativa? Revista Qurriculum, La Laguna, v. 25, p. 29-56, 2012. Disponível em: http://www.if.ufrgs.br/ moreira/oqueeafinal.pdf. Acesso em: 05 abr. 2018.

NOVAK, Joseph Donald. Learning, creating, and using knowledge: concept maps as facilitative tools in schools and corporations, NY: Routledge, 2010.

OLIVEIRA, Jane Raquel Silva de; QUEIROZ, Salete Linhares. Construção participativa do material didático "Comunicação e linguagem científica: guia para estudantes de Química". Electrónica de Enseñanza de las Ciencias, Vigo, v. 6, n. 3, 2007, p. 673-690. Disponível em: https://dialnet.unirioja.es/servlet/articulo?codigo=2470947. Acesso em 17 jul. 2019. 
ONTORIA, Antônio.; LUCKE, Angela de.; GÓMEZ, Juan Pedro R. Aprender com Mapas Mentais: Uma estratégia para pensar e estudar. São Paulo: Madras, 2006.

ROGERS, Carl Ransom. Tornar-se pessoa. 5a. Ed. São Paulo: Martins, 2001.

SARAIVA, Francisco Alberto et al. Atividade Experimental como Proposta de Formação de Aprendizagem Significativa no Tópico de Estudo de Soluções no Ensino Médio. Revista Thema, v. 14, n. 2, p 194 - 208, 2017. https://doi.org/10.15536/thema.14.2017.194-208.424. Acesso em: 29 abr. 2021.

SARAIVA, Francisco Alberto. Concentração de Soluções no Ensino Médio: O uso de Atividades Experimentais para uma Aprendizagem Significativa. 2017. 94 f. Dissertação (Mestrado em Ensino de Ciências e Matemática) - Instituto Federal de Educação, Ciência e Tecnologia do Ceará, Fortaleza, 2017. Disponível em: http://pgecm.fortaleza.ifce.edu.br/wpcontent/uploads/2017/06/Disserta\%C3\%A7\%C3\%A3o-Alberto-Saraiva-2017.pdf. Acesso em: 30 abr. 2021 